Gut, 1977, 18, 105-110

\title{
Effect of fundic distension on gastric acid secretion in man
}

\author{
U GRÖTZINGER, S. BERGEG ̊RDH, AND L. OLBE \\ From the Department of Surgery II, University of Göteborg, Sahlgren's Hospital, Göteborg, Sweden
}

SUMMARY The effect of distension of the fundus and body of the stomach on gastric acid secretion was studied in 26 patients with duodenal ulcer and six healthy subjects. Graded distension produced by inflating a rubber balloon to volumes of 150,300 , and $600 \mathrm{ml}$ resulted in significant sequential increments of acid output. The secretory response outlasted stimulation by at least one hour. In both groups of subjects, the highest acid output obtainable with fundic distension amounted to just above $50 \%$ of the maximum secretory response evoked by intravenous infusion of pentagastrin. A significant correlation was found between the peak secretory rates observed during fundic distension and after pentagastrin stimulation. It is concluded that distension of the oxyntic gland area in man is a potent stimulus for gastric secretion of acid and that patients with duodenal ulcer are no more sensitive to this stimulus than healthy subjects.

Food reaching the stomach stimulates the parietal cells to secrete hydrochloric acid by virtue of its physicochemical properties-that is, by activating enteroceptors which are susceptible to chemical and mechanical stimuli. In the dog, mechanical stimulation by gastric distension brings about acid secretion by means of two mechanisms: direct neural activation of the oxyntic glands and pH-dependent release of antral gastrin (Grossman, 1967). This basic concept of dual reflex action applies to both antral and fundic distension (Grossman, 1961, 1962; Debas et al., 1974; Debas et al., 1975). In man, the acid response to the ingestion of test meals has been extensively studied (Hunt and Macdonald, 1952; Rune, 1966; George, 1968; Cooke, 1970; Fordtran and Walsh, 1973; Malagelada et al., 1976). This integrated secretory response is influenced by factors including psychic stimulation, the volume and composition of the meal, the rate of gastric emptying and the effects of chyme on the intestine. Only sparse information is available on the acid secretory effect of the different components which constitute the gastric phase in man. Recent work has shown that antral distension stimulates acid secretion in patients with duodenal ulcer by way of a mechanism which is $\mathrm{pH}$-independent and not mediated by gastrin (Bergegårdh et al., 1975, 1976b). In contrast, healthy subjects did not respond to antral distension.

Received for publication 10 September 1976
In the present study, the acid secreting part of the stomach was distended with a balloon and the effect of graded fundic distension on acid secretion was examined in patients with duodenal ulcer and in healthy subjects.

\section{Methods}

\section{SUBJECTS STUDIED}

Patients with duodenal ulcer (DU)

Twenty-six male subjects (mean age 44 years, range 20-63 years) with chronic duodenal ulceration awaiting elective surgery were studied. The diagnosis was established by endoscopy and/or barium meal examination and confirmed at operation. In no patient was there any evidence of gastric outlet obstruction.

\section{Healthy subjects}

Six healthy men (mean age 23 years, range 20-25 years) without any history of gastrointestinal disease or other relevant illness volunteered to enter the study.

Care was taken to inform each subject about the purely scientific interest of the experiments and informed consent was obtained. The investigation has been approved by the Ethical Committee of the Faculty of Medicine, University of Göteborg.

EXPERIMENTAL PROCEDURES

Determination of gastric acid output

Pentagastrin infusion and fundic distension experi- 


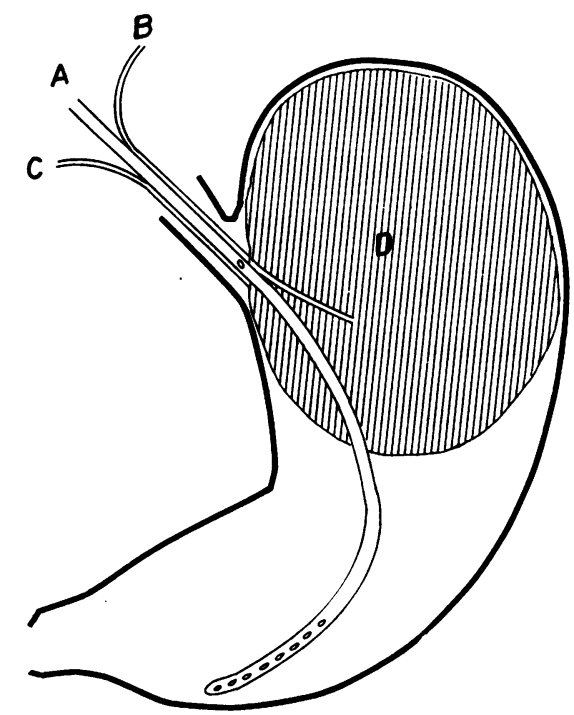

Fig. 1 Diagram showing the method used in fundic distension experiments. Gastric contents are aspirated via a double lumen nasogastric tube $(A)$. Phenol red solution is infused through a small calibre tube $(B)$. Another polyethylene tube $(C)$ is connected with a rubber balloon $(D)$ which is inflated with air to distend the gastric fundus and body. For details see text.

ments were performed in random order on different days, not more than one week apart. Any anticholinergic therapy was discontinued two days before the tests. After at least 12 hours' fasting the subjects were seated comfortably in a semirecumbent position. A double lumen nasogastric tube (Salem sump tube no. 14) was passed with its tip located in the most dependent part of the stomach as checked by fluoroscopy. Residual gastric contents were carefully aspirated and discarded. In order to correct for losses of gastric juice to the duodenum, phenol red in water $(8 \mathrm{mg} / \mathrm{l})$ was used as a marker. Throughout the experiments this solution was pumped into the stomach at a constant rate of $225 \mathrm{ml}$ per $15 \mathrm{~min}$ via a thin polyethylene tube (Intramedic PE 160) which was fitted to the nasogastric tube and placed with its tip $5-10 \mathrm{~cm}$ below the oesophagogastric junction (Fig. 1). The rather high perfusion volume was used to facilitate the mixing of gastric secretions and marker solution. Gastric juice and phenol red solution were continuously aspirated using an electric suction pump giving intermittent negative pressure ( $-50 \mathrm{~mm} \mathrm{Hg}$ ) once per second. Free flow through the tube was ensured by occasional constant suction and manual air insufflation through the intrinsic air vent tube. When aspiration through the nasogastric tube was continued after the infusion of the marker solution had been stopped, only traces of phenol red could be detected, demonstrating the efficiency of the suction system. This indicates that only a minimal volume of fluid was present in the stomach at any particular time.

The continuously aspirated gastric contents were divided into 15-minute samples and the volume and $\mathrm{pH}$ were recorded. The amount of acid recovered was determined by titrating $100-\mathrm{ml}$ aliquots to $\mathrm{pH} 7 \cdot 0$, using $0 \cdot 1 \mathrm{~mol} / 1 \mathrm{NaOH}$ in a Radiometer Autoburette. The phenol red concentration was measured in 4-ml aliquots using a Beckman spectrophotometer at wave length $565 \mathrm{~nm}$ after filtration (Millipore filter $1.2 \mu \mathrm{m})$ and alkalinisation with a few drops of concentrated $\mathrm{NaOH}$. The percentage recovery of phenol red could thus be estimated for each 15-minute sample. On the assumption that homogeneous mixing had been achieved, the amount of acid secreted could be calculated. All results given below are corrected for pyloric losses. The available data did not permit us to make allowance in these calculations for duodenal-gastric reflux.

\section{Fundic distension}

A thin-walled rubber balloon was attached to the nasogastric tube $20 \mathrm{~cm}$ from its tip and connected with a thin polyethylene tube which was snugly tied to the nasogastric tube (Fig. 1). The balloon could be inflated with air, volume changes being produced over a five-minute period using a $100 \mathrm{ml}$ syringe. Each balloon assembly was tested for leaks before the experiment and by checking the amount of air withdrawn when distension was released. The balloon was easily identified by fluoroscopy and its position was frequently checked throughout the test. The subjects were encouraged to take an occasional deep breath or to slightly change position. One additional aspiration hole was cut in the nasogastric tube, interrupting its radio-opaque thread. This hole was sited just below the oesophagogastric junction, its positon being verified by fluoroscopy. With these measures, any pooling of gastric contents between the inflated balloon and the stomach wall could be minimised. During distension, the percentage marker recovery was not higher than under basal conditions and was in agreement with the values observed in antral balloon distension experiments (Bergegårdh and Olbe, 1975).

In pilot studies, it was found that distension volumes of 800 or $900 \mathrm{ml}$ regularly induced epigastric fullness, pain or even nausea and occasionally retching. In the presence of these symptoms the acid output was markedly depressed. The volumes chosen for the study were generally well tolerated. A few subjects experienced discomfort during the experiment and these results were excluded. In two patients with DU, intrinsic balloon pressure was 
Fundic distension

$150 \mathrm{ml} 300 \mathrm{ml} 600 \mathrm{ml}$

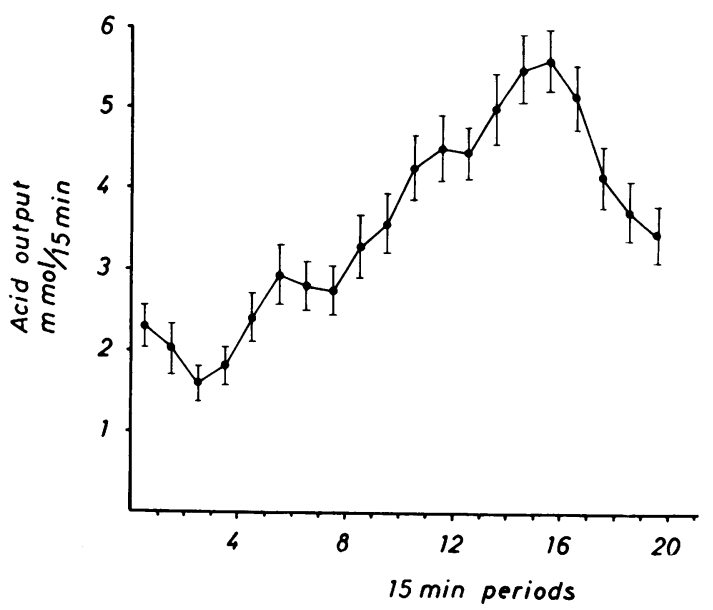

Fig. 2 The acid secretory pattern induced by fundic distension in 26 patients with DU. Means in mmol/15 min. The vertical bars indicate the standard errors of the means.

continuously monitored using a Statham transducer and recorded on a Mingograph. The pressure exerted on the gastric wall did not exceed $15 \mathrm{~cm} \mathrm{H}_{2} \mathrm{O}$ and did not rise with increasing distension volumes.

Basal acid output was recorded during at least 45 minutes. The balloon was then inflated to volumes of 150,300 , and $600 \mathrm{ml}$, each level of distension being maintained for one hour. After distension had been released, acid secretion was collected for another hour. The mean value of the last two 15-minute periods under basal conditions, during distension with 150,300 , and $600 \mathrm{ml}$, and in the post-distension period, was taken to represent the acid output during the corresponding step of the experiment. The mean of the two highest subsequent 15-minute values observed at any time during distension denotes the peak acid output produced by fundic distension (PAO dist).

\section{Pentagastrin infusion}

Basal secretions were collected for one hour. Pentagastrin (Peptavlon, ICI) was then infused intravenously in a dose of $90 \mu \mathrm{g} / \mathrm{h}$ for 45 minutes followed by $300 \mu \mathrm{g} / \mathrm{h}$ for a further 60 minutes. The peak acid output after pentagastrin stimulation $\left(\mathrm{PAO}_{\mathrm{pg}}\right)$ was defined as the mean of the two highest consecutive 15-minute values. Dose-response studies performed in this laboratory (Bergegårdh et al., 1976a) have shown that the observed PAO $_{\mathrm{pg}}$ amounts to roughly $90 \%$ of the calculated maximal response to

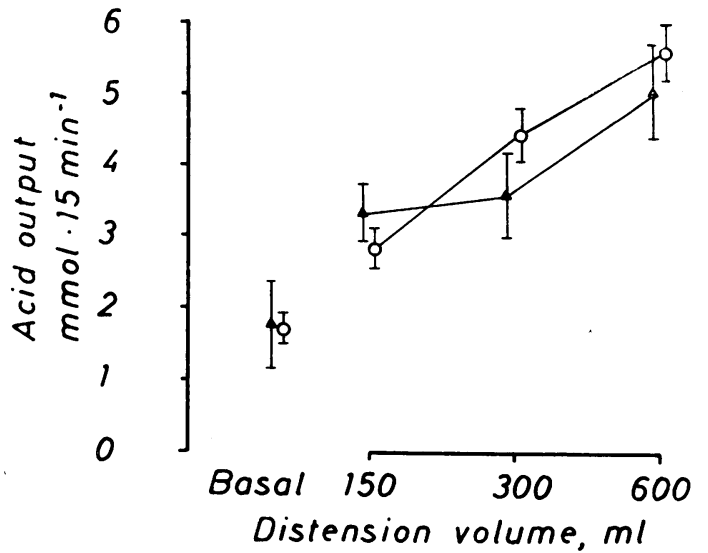

Fig. 3 Acid responses to graded fundic distension in 26 patients with $D U(\bigcirc)$ and in six healthy young men $(\Delta)$. Means in mmol/15 min. Vertical bars: SEM.

Table Gastric acid responses to graded fundic distension and to intravenous pentagastrin in 26 patients with $D U$ and six healthy subjects (means $\pm S D$, mmol/15 min)

\begin{tabular}{|c|c|c|}
\hline & DU patients & Healthy subjects \\
\hline $\begin{array}{l}\text { Basal } \\
\text { Distension (ml) }\end{array}$ & $1.7 \pm 1 \cdot 1$ & $1.7 \pm 1.5$ \\
\hline 150 & $2 \cdot 8 \pm 1 \cdot 4$ & $3 \cdot 3 \pm 1 \cdot 0$ \\
\hline 300 & $4.4 \pm 1.9$ & $3.5 \pm 1.5$ \\
\hline 600 & $5.6 \pm 2.0$ & $5.0 \pm 1.6$ \\
\hline Post-distension & $3.6 \pm 1.7$ & $3 \cdot 3 \pm 1 \cdot 1$ \\
\hline PAO dist $_{\text {dis }}$ & $5.9 \pm 2 \cdot 1$ & $5 \cdot 3 \pm 1.3$ \\
\hline $\mathrm{PAO}_{\mathrm{pg}}$ & $11.0 \pm 2.5$ & $10 \cdot 9 \pm 2.0$ \\
\hline$\frac{\mathrm{PAO}_{\mathrm{dist}}}{\mathrm{PAO}_{\mathrm{pg}}} \cdot 100$ & $53 \cdot 3 \pm 14 \cdot 5$ & $50 \cdot 1 \pm 15 \cdot 8$ \\
\hline
\end{tabular}

as an approximation for the maximal secretory capacity.

\section{Statistical evaluation}

In both groups of subjects the individual values of the different steps of the experiment were compared on a computer by analysis of variance for paired data followed by the multiple comparison technique of Scheffé (Morrison, 1967). Correlations were examined by regression analysis. Student's $t$ test and the Mann-Whitney U-test were used when appropriate.

\section{Results}

\section{Patients with $D U$}

In 26 patients with DU, graded fundic distension uniformly caused a prompt rise in the secretory rate, which then levelled off and was reasonably stabilised during the last two 15-minute periods at each distension volume (Fig. 2). When distension was released, the acid output decreased rapidly but did not fall to 
basal levels within the observation time, showing that the response outlasted stimulation. Mean basal secretion was $1.7 \mathrm{mmol} / 15 \mathrm{~min}$. Fundic distension with 150,300 , and $600 \mathrm{ml}$ lead to significant $(P<$ 0.01 ) sequential increments in acid output with mean values of $2 \cdot 8,4 \cdot 4$, and $5.6 \mathrm{mmol} / 15 \mathrm{~min}$, respectively (Table, Fig. 3). The post-distension secretory rate (mean $3.6 \mathrm{mmol} / 15 \mathrm{~min}$ ) was significantly ( $P<$ 0.001 ) different from both basal acid output and 600-ml response. The individual peak acid responses were usually observed during distension with $600 \mathrm{ml}$ (in 23 out of 26 patients, and during $300-\mathrm{ml}$ distension in the remaining three) and averaged $5.9 \mathrm{mmol} /$ $15 \mathrm{~min}$, corresponding to $53.3 \%$ of the mean $\mathrm{PAO}_{\mathrm{pg}}$ $(11.0 \mathrm{mmol} / 15 \mathrm{~min})$. The peak responses to fundic distension and pentagastrin infusion were found to be significantly $(r=0.69, \mathrm{P}<0.001)$ correlated (Fig. 4).

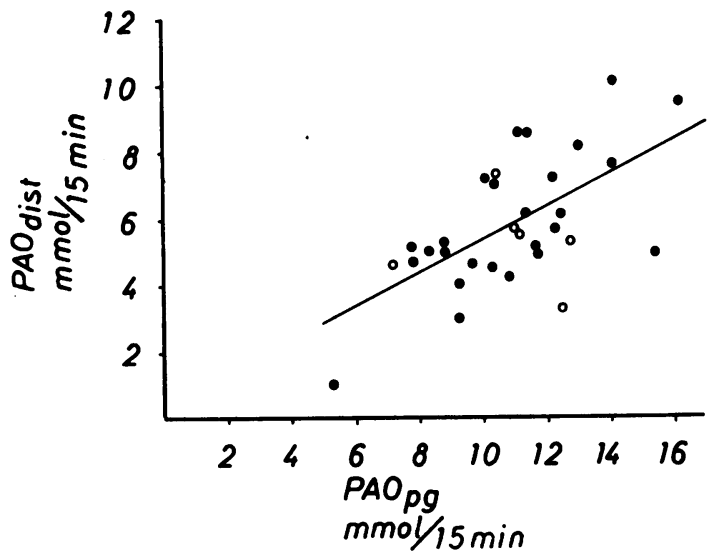

Fig. 4 Correlation between peak acid output after maximum pentagastrin stimulation and peak acid response to fundic distension in 26 patients with $D U$ (O) and six healthy subjects (O). For all 32 subjects the equation of the regression line is $y=0.32+$ $0.50 x$ and $r=0.61(\mathrm{P}<0.001)$. For the 26 patients with $D U$ the regression line (not shown) is $y=0.57 x-$ 0.36 and $r=0.69(\mathrm{P}<0.001)$.

The $\mathrm{pH}$ of the gastric contents was between $2 \cdot 0$ and 2.7 under basal conditions and fell to $1 \cdot 6-2 \cdot 0$ during distension with $600 \mathrm{ml}$.

The mean phenol red recovery amounted to $86 \%$ under basal conditions, 86, 86, and $85 \%$ during distension with 150,300 , and $600 \mathrm{ml}$, respectively, and rose to $90 \%$ in the post-distension hour. In the pentagastrin infusion tests the phenol red recovery averaged $91 \%$.

Healthy subjects

In six healthy young men, graded fundic distension produced a stepwise increase of acid output in a

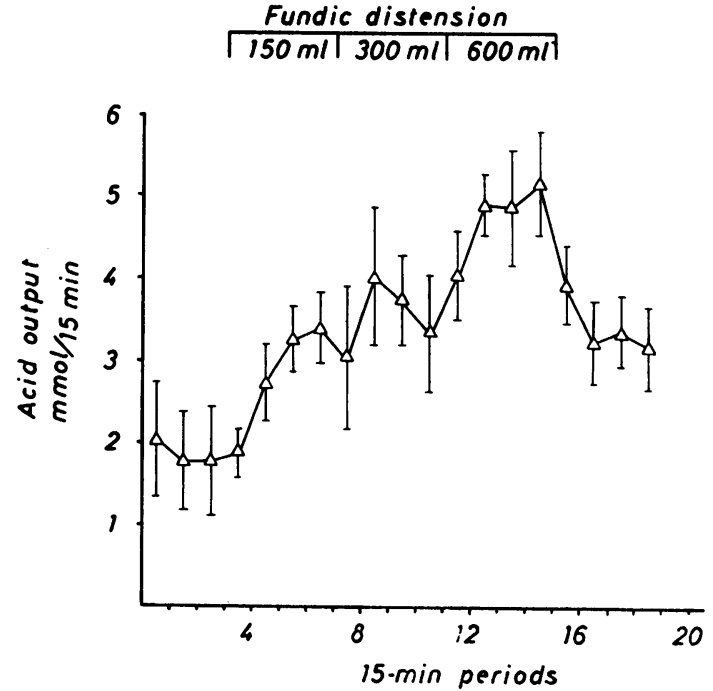

Fig. 5 The pattern of acid secretion in fundic distension experiments in six healthy subjects. Means in mmol/15 min. The vertical bars represent the standard errors of the means.

manner which was very similar to that observed in patients with DU, although with $300-\mathrm{ml}$ distension the pattern was somewhat erratic (Fig. 5). Mean basal acid output was $1.7 \mathrm{mmol} / 15 \mathrm{~min}$. Fundic distension with 150,300 , and $600 \mathrm{ml}$ caused significant $(P<0.05)$ increases to $3.3,3.5$, and $5.0 \mathrm{mmol} /$ $15 \mathrm{~min}$, respectively, although the difference between the $150-\mathrm{ml}$ and $300-\mathrm{ml}$ responses was not statistically significant (Table, Fig. 3). The mean postdistension acid output amounted to $3.3 \mathrm{mmol} / 15$ min and was significantly $(P<0.05)$ different from both basal secretion and $600-\mathrm{ml}$ response. With the exception of one case, the highest individual secretory rate was observed during distension with 600 ml. The mean PAO dist was $5.3 \mathrm{mmol} / 15 \mathrm{~min}$ or $50.1 \%$ of the peak acid output after pentagastrin stimulation $(10.9 \mathrm{mmol} / 15 \mathrm{~min}$, Table). The relation between the peak responses to fundic distension and to pentagastrin infusion in this small group of subjects is shown in Fig. 4.

The $\mathrm{pH}$ of the gastric contents was between $2 \cdot 1$ and 2.9 under basal conditions and fell to 1.6-2.0 during $600 \mathrm{ml}$ distension.

The mean phenol red recovery was $82 \%$ during basal, 86,87 , and $88 \%$ during distension with 150 , 300 , and $600 \mathrm{ml}$, respectively, and $89 \%$ post-distension. In the pentagastrin infusion tests, the mean marker recovery amounted to $91 \%$.

No significant differences were found between patients with DU and healthy subjects when comparing either observed secretory values (Table) or 
percentage figures after normalisation of the secretory data with regard to the individual $\mathrm{PAO}_{\mathrm{pg}}$.

\section{Discussion}

The acid secretory response to the ingestion of a meal is the net result of interacting stimulatory and inhibitory mechanisms arising during the cephalic, gastric, and intestinal phases (Lim et al., 1925; Malagelada et al., 1976). Part of the gastric phase is activated mechanically by virtue of the meal volume (Hunt and Macdonald, 1952; George, 1968; Cooke, 1970). Distension of the human stomach brings about reflex mechanisms resulting in acid secretion as well as in gastric receptive relaxation (Jahnberg et al., 1975; Stadaas, 1975) and pancreatic enzyme and water secretion (White et al., 1963). Our knowledge concerning the mechanisms by which distension of either the oxyntic or pyloric gland area activates the parietal cells to secrete acid stems mostly from animal experiments. In the dog, fundic distension entails cholinergic oxynto-oxyntic reflexes running in short intramural and long vagovagal pathways (Grossman, 1961; 1962). Preshaw (1970) demonstrated that the distension response partly depended on the antral $\mathrm{pH}$ and on the integrity of antral innervation. Recently, an oxynto-pyloric, probably vagovagal, reflex for release of antral gastrin has been discovered (Debas et al., 1975, Debas and Grossman, 1975).

In the present study, graded fundic distension resulted in volume-related secretory responses in patients with DU as well as in healthy subjects. This is in agreement with the observations of other workers who used liquid test meals distending the whole stomach (Hunt and Macdonald, 1952; Cooke, 1970). Apparently, motor effects were evoked as well. Presumably because of reflex relaxation of the gastric fundus and body (Jahnberg et al., 1975; Stadaas, 1975), the transmural pressure remained unchanged in the two DU patients examined, although the distending volume was quadrupled.

It is recognised that the experimental model used in this study is not really 'physiological' in that distension was increased with time, whereas the reverse order of events takes place during the digestion of a meal. It was found that the response uniformly outlasted stimulation, a phenomenon also observed in sham feeding experiments in man (Knutson and Olbe, 1973). Up to one hour after relief of distension, the secretory rate was still of a magnitude corresponding to the response to $300-\mathrm{ml}$ distension. This pattern of prolonged responses precludes the use of diminishing graded distension in a single test.

The application of dose-response data to a suitable kinetic model provides a valuable tool for the determination of stimulant-receptor interactions (Makhlouf, 1973) and allows one to characterise ulcer patients as compared with normal man (Isenberg et al., 1975). Obviously, the precise definition of the stimulant in quantitative and qualitative terms is a prerequisite. Electrophysiological evidence obtained in a number of animals (Paintal, 1954; Iggo, 1955) indicates that distension of the stomach activates slowly adapting tension receptors causing an increased discharge in vagal afferent fibres. These specialised enteroceptors, probably located in, and 'in series' with, the muscularis propria (Iggo, 1957) respond to tangential lengthening of the gastric wall rather than to the distending volume as such (Leek, 1972). Hence, this distension effect is exerted by changes in tension which, according to the law of Laplace is determined by the prevailing transmural pressure, the distending volume, and the geometrical form of the organ. Since the shape of the stomach and the surface under exposure will change during graded balloon distension of the intact organ, the tensions actually generated are difficult to determine. It would be questionable to quantify the stimulus in terms of distending volumes in order to establish a dose-response relationship for acid responses to fundic distension. We did not find any significant differences between healthy subjects and DU patients when comparisons were based on either observed data for acid output or when the responses were normalised with regard to the individual peak acid output after pentagastrin stimulation. This observation may indicate that patients with DU are no more sensitive to fundic distension than normal man. In contrast, patients with DU have been shown to have an increased responsiveness to pentagastrin stimulation (Isenberg et al., 1975) and to antral distension (Bergegårdh and Olbe, 1975).

The observed peak acid response to fundic distension averaged about half the $\mathrm{PAO}_{\mathrm{pg}}$ in both healthy subjects and patients with DU (Table), showing that mechanical activation of the parietal cell area alone is a potent secretory stimulus in man. Moreover, there was a significant positive correlation between the peak acid outputs during fundic distension and after pentagastrin stimulation in patients with DU. The intercept of the regression line was not significantly different from zero, and its slope indicates that the mean PAO dist amounts to $57 \%$ of the mean PAO $_{\text {pg. In agreement with the observations of others }}$ (Hunt and Macdonald, 1952; Cooke, 1970) we found in pilot studies that vigorous distension with balloon volumes of $800-900 \mathrm{ml}$ dampened rather than enhanced the secretory rate. This may well be due to non-specific inhibition since the subjects experienced epigastric fullness and pain or nausea.

In the dog, mechanical activation of the pyloric 
antrum is a powerful stimulus for gastrin release and acid secretion (Woodward et al., 1957; Debas et al., 1974). Antral distension fails to stimulate acid secretion in normal man and produces only a moderate response in ulcer patients, apparently without liberation of gastrin (Bergegårdh and Olbe, 1975; Bergegårdh et al., 1976b). In gastric fistula dogs with innervated antral pouches, Preshaw (1970) found that the peak response to fundic distension amounted to $42 \%$ of the highest acid output after stimulation with exogenous gastrin. Our findings indicate that mechanical activation of the oxyntic gland area in man is a secretory stimulus at least as potent as in the dog. In contrast with the observations on antral distension, there is no significant difference between normal subjects and patients with DU.

We wish to thank Ms Eva Lindberg and Mrs Ingrid Grähs for expert technical assistance. The investigation was supported by a grant (project no. 17X-760) from the Swedish Medical Research Council. U.G. held a fellowship from Margarete und Walther Lichtenstein-Stiftung, Basel, Switzerland.

\section{References}

Bergegårdh, S., Broman, G., Knutson, U., Palmer, L., and Olbe, L. (1976a). Gastric acid responses to graded i.v. infusion of pentagastrin and Histalog in peptic ulcer patients before and after antrum-bulb resection. Scandinavian Journal of Gastroenterology, 11, 337-346.

Bergegårdh, S., Knutson, U., and Olbe, L. (1975). The effect of intragastric neutralization on the gastric acid response to antral distension in man. Scandinavian Journal of Gastroenterology, 10, 625-631.

Bergegårdh, S., Nilsson, G., and Olbe, L. (1976b). The effect of antral distension on acid secretion and plasma gastrin in duodenal ulcer patients. Scandinavian Journal of Gastroenterology, 11, 475-479.

Bergegårdh, S., and Olbe, L. (1975). Gastric acid response to antrum distension in man. Scandinavian Journal of Gastroenterology, 10, 171-176.

Cooke, A. R. (1970). Potentiation of acid output in man by a distention stimulus. Gastroenterology, 58, 633-637.

Debas, H. T., and Grossman, M. I. (1975). Chemicals bathing the oxyntic gland area stimulate acid secretion in dog. Gastroenterology, 69, 654-659.

Debas, H. T., Konturek, S. J., Walsh, J. H., and Grossman, M. I. (1974). Proof of a pyloro-oxyntic reflex for stimulation of acid secretion. Gastroenterology, 66, 526-532.

Debas, H. T., Walsh, J. H., and Grossman, M. I. (1975). Evidence for oxyntopyloric reflex for release of antral gastrin. Gastroenterology, 68, 687-690.

Fordtran, J. S., and Walsh, J. H. (1973). Gastric acid secretion rate and buffer content of the stomach after eating. Results in normal subjects and in patients with duodenal ulcer. Journal of Clinical Investigation, 52, 645-657.

George, J. D. (1968). Gastric acidity and motility. American Journal of Digestive Diseases, New Series, 13, 376-383.
Grossman, M. I. (1961). Stimulation of secretion of acid by distention of denervated fundic pouches in dogs. Gastroenterology, 41, 385-390.

Grossman, M. I. (1962). Secretion of acid and pepsin in response to distention of vagally innervated fundic gland area in dogs. Gastroenterology, 42, 718-721.

Grossman, M. I. (1967). Neural and hormonal stimulation of gastric secretion of acid. In Handbook of Physiology, Section 6: Alimentary Canal, volume II. Secretion, pp. 835-863. Edited by C. F. Code. American Physiological Society: Washington, D.C.

Hunt, J. N., and Macdonald, I. (1952). The relation between the volume of a test-meal and the gastric secretory response. Journal of Physiology, 117, 289-302.

Iggo, A. (1955). Tension receptors in the stomach and the urinary bladder. Journal of Physiology, 128, 593-607.

Iggo, A. (1957). Gastro-intestinal tension receptors with unmyelinated afferent fibres in the vagus of the cat. Quarterly Journal of Experimental Physiology, 42, 130-143.

Isenberg, J. I., Grossman, M. I., Maxwell, V., and Walsh, J. H. (1975). Increased sensitivity to stimulation of acid secretion by pentagastrin in duodenal ulcer. Journal of Clinical Investigation, 55, 330-337.

Jahnberg, T., Martinson, J., Hultén, L., and Fasth, S. (1975). Dynamic gastric response to expansion before and after vagotomy. Scandinavian Journal of Gastroenterology, 10, 593-598.

Knutson, U., and Olbe, L. (1973). Gastric acid response to sham feeding in the duodenal ulcer patient. Scandinavian Journal of Gastroenterology, 8, 513-522.

Leek, B. F. (1972). Abdominal visceral receptors. In Handbook of Sensory Physiology, volume III/I, Enteroceptors, pp. 113-160. Edited by E. Neil. Springer: Berlin.

Lim, R. K. S., Ivy, A. C., and McCarthy, J. E. (1925). Contributions to the physiology of gastric secretion. I: Gastric secretion by local (mechanical and chemical) stimulation. Quarterly Journal of Experimental Physiology, 15, 13-53.

Makhlouf, G. M. (1973). Dose-response curves to gastric secretory stimulants in man. In International Encyclopedia of Pharmacology and Therapeutics. Section 39A, Pharmacology of Gastrointestinal Motility and Secretion, vol. I, pp. 173-194. Edited by P. Holton. Pergamon Press: Oxford.

Malagelada, J.-R., Longstreth, G. F., Summerskill, W. H. J., and Go, V. L. W. (1976). Measurement of gastric functions during digestion of ordinary solid meals in man. Gastroenterology, 70, 203-210.

Morrison, D. M. (1967). Multivariate Statistical Methods. McGraw-Hill: New York.

Paintal, A. S. (1954). A study of gastric stretch receptors. Their role in the peripheral mechanism of satiation of hunger and thirst. Journal of Physiology, 126, 255-270.

Preshaw, R. M. (1970). Influence of the antrum on the acid response to distension of the body of the stomach in dogs. Canadian Journal of Physiology and Pharmacology, 48, 661669.

Rune, S. J. (1966). Comparison of the rates of gastric acid secretion in man after ingestion of food and after maximal stimulation with histamine. Gut, 7, 344-350.

Stadaas, J. O. (1975). Intragastric pressure/volume relationship before and after proximal gastric vagotomy. Scandinavian Journal of Gastroenterology, 10, 129-134.

White, T. T., McAlexander, R. A., and Magee, D. F. (1963). The effect of gastric distension on duodenal aspirates in man. Gastroenterology, 44, 48-51.

Woodward, E. R., Robertson, C., Fried, W., and Schapiro, H. (1957). Further studies on the isolated gastric antrum. Gastroenterology, 32, 868-877. 